\title{
LETTERS
}

\section{The Patient and Patient-Centered Medical Homes}

\author{
Maret Felzien, $\mathrm{MA}^{7}$, Linda Zittleman, $\mathrm{MSPH}^{2}$, and John M. Westfall, MD, MPH ${ }^{2,3}$

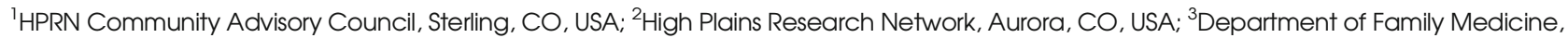 \\ University of Colorado Aschutz Medical Campus, Aurora, CO, USA.
}

$J$ Gen Intern Med 31(4):363

DOI: $10.1007 / \mathrm{s} 11606-015-3561-6$

(c) Society of General Internal Medicine 2015

$\mathrm{D}$ ear Editor,

We applaud Aysola et al., ${ }^{1}$ and are excited to see others considering the patient perspective on the patient-centered medical home (PCMH). We agree that patients should help decide what "patient-centered" really means. Aysola reported that most patients lack any awareness of PCMH concepts. In fact, in the eyes of patients, PCMH is overly complicated and is often viewed as a misnomer in its "patient-centered" title. This PCMH health care delivery model is ponderous, complex and mysterious, and despite its name, it takes shape from the practice and provider rather than the patient

The High Plains Research Network (HPRN) undertook a community-engaged research project to translate the complexities of the formal PCMH into patient-centered language and messages. During the 9-month project, community members went through Boot Camp Translation, ${ }^{2}$ learned about PCMH, brainstormed what it really means for patients, and undertook an appreciative inquiry process to identify the patient-centered aspects of PCMH. Their final PCMH-translated message was "Medical Home is Relationship." The group of farmers, ranchers, schoolteachers, and others created a poster to provide this message to practices and patients in rural eastern Colorado. Ongoing PCMH practice transformation efforts use these messages as part of their practice coaching. Patients can help our practices and healthcare systems create a PCMH that is truly patient-centered. ${ }^{4}$

Aysola et al. discuss the most important point to patients - their relationship with their primary care provider. This theme became the focal point for the HPRN communities. The community members participating in the research project placed emphasis on the patient-physician relationship, and concluded that the individual practice and provider components of the PCMH should exist "in service to that relationship".

By including the perspective of patients/community members in the discussion and implementation of PCMH, the true value of patient-centeredness can be a guiding principle for improved patient care and health outcomes. By involving the patient voice, this complex system of practice, provider, and team accreditation standards can still hold central the focus on the patient-provider relationship and ensure that the name "PCMH" describes the actual patient experience.

Corresponding Author: John M. Westfall, MD, MPH; Department of Family MedicineUniversity of Colorado Aschutz Medical Campus, F496, Academic Office 1, 12631 E 17th Avenue, Aurora, CO 80045, USA (e-mail: jack.westfall@ucdenver.edu).

\section{Compliance with Ethical Standards:}

Conflict of Interest: All authors declare no conflicts of interest.

\section{REFERENCES}

1. Aysola J, Werner RM, Keddem S, SoRelle R, Shea JA. Asking the patient about patient-centered medical homes: a qualitative analysis. J Gen Int Med. 2015;30(10):1461-7.

2. Norman N, Bennett C, Cowart S, Felzien M, Flores M, Flores R, Haynes C, Hernandez M, Rodriquez MP, Sanchez N, Sanchez S, Winkelman K, Winkelman S, Zittleman L, Westfall JM. Boot camp translation: a method for building a community of solution. Am Board Fam Med. 2013;26:254-63.

3. Allison C, Zittleman L, Ringel M, Felzien M, Bennett C, Cowart S, Flores M, Flores R, Hernandez M, Norman N, Rodriquez MP, Sanchez N, Sanchez S, Winkelman K, Winkelman S, Sutter C, Gale S, Westfall JM. Translating the medical home into patient-centred language. London J Prim Care (Abingdon). 2014;6(6):124-30.

4. Westfall JM, Zittleman L, Ringel M, Sutter C, McCaffrey K, Gale S, Gerk T, Sanchez S, LeBlanc W, Dickinson LM, Dickinson P. How do rural patients benefit from the patient-centred medical home? A card study in the High Plains Research Network. London J Prim Care (Abingdon). 2014;6(6): 136-48. 